BENM 2021

International Scientific and Practical Conference "Biotechnology, Ecology, Nature Management"

\title{
ENVIRONMENTAL RESPONSIBILITY OF THE CORPORATION WITHIN THE FRAMEWORK OF SUSTAINABLE DEVELOPMENT
}

\author{
Gaidarenko L. V. (a)*, Kapitsa G. P. (b), Lyubovskaya N. M. (c) \\ *Corresponding author
}

(a) K.G. Razumovsky Moscow State University of Technologies and Management (the First Cossack University), 73, Zemlyanoy Val str., Moscow, Russia, gaydarenkolv@mgutm.ru

(b) K.G. Razumovsky Moscow State University of Technologies and Management (the First Cossack University), 73, Zemlyanoy Val str., Moscow, Russia

(c) K.G. Razumovsky Moscow State University of Technologies and Management (the First Cossack University), 73, Zemlyanoy Val str., Moscow, Russia

\begin{abstract}
The paper reveals the theoretical and methodological aspects of the essence, meaning and directions of assessing the environmental responsibility of a corporation within the framework of the concept of sustainable development. The author substantiates the relevance of the corporation's environmental responsibility in the current conditions of the functioning of socio-economic systems in the context of the concept of sustainable development, highlights the most significant priorities of environmental corporate responsibility, reflecting the general vector of the functioning of the socio-economic system to achieve the trajectory of sustainable development, characterizes the motivational criteria and principles of responsible behavior business structures in the field of environmental development, considers the key aspects of the methodological basis for diagnosing the current level of environmental responsibility of corporations. The study concludes that it is necessary to expand the potential of the company's environmental management to reduce the negative anthropogenic impact on ecosystems of different levels. Achieving the goals of sustainable environmental development of the corporation becomes possible by increasing the capacity of environmental budgets, increasing the scale of environmental monitoring, using resource-saving technologies, and introducing the conceptual foundations of "green" management. The expansion of corporate environmental competencies is becoming an important tool for ensuring the sustainability of the functioning of the socio-economic system with a balanced use of the resource potential, primarily due to the rationality of the current consumption of its main elements.
\end{abstract}




\section{Introduction}

For the existing conditions of doing business, a characteristic aspect is the presence of a high level of intensity of anthropogenic impact on the environment. The world community sees the solution to this issue in the formation of a common trajectory for sustainable development of socio-economic systems. The transition to sustainable development is a necessary strategic alternative, the achievement of which is of vital importance for all of humanity. An important tool for achieving sustainable development goals is the mechanism of corporate environmental responsibility. The environmental responsibility of corporations is an extremely capacious concept that includes a large-scale list of issues of various impact vectors. In its most general form, environmental responsibility is a certain set of characteristics of corporate behaviour, for which the priority is to achieve a minimum impact on the environment within the framework of economic and economic activities, as well as to reduce the likelihood of environmental risks. Formation of the ecological trajectory of the company's functioning is a rather long and step-by-step process that requires the presence of an integrated strategic approach in the context of the specifics of economic and economic activities.

\section{Problem Statement}

The implementation of strategic changes to ensure the achievement of the required level of corporate environmental responsibility should be gradual and correlated with the interests of all stakeholders. The pivot of the motives of corporate environmental responsibility is the need to preserve the natural and ecological potential for future generations, subject to the solution of pressing problems of the current progressive development of socio-economic systems.

\section{Purpose of the Study}

The purpose of the work is to study the theoretical and methodological aspects of the essence, meaning and directions of assessing the environmental responsibility of corporations within the framework of the concept of sustainable development. Achievement of this goal occurs as a result of solving the following list of tasks:

-to substantiate the relevance of the corporation's environmental responsibility in the current conditions of functioning of socio-economic systems in the context of the concept of sustainable development;

-to highlight the most significant priorities of environmental corporate responsibility, reflecting the general vector of the functioning of the socio-economic system to achieve the trajectory of sustainable development;

-to characterize the motivational criteria and principles of responsible behavior of business structures in the field of environmental development;

-to consider the key aspects of the methodological basis for diagnosing the current level of corporate environmental responsibility. 


\section{Research Methods}

In the process of performing the work, a number of research methods were used, the main of which were the methods of generalization and synthesis, scientific abstraction, comparison, selective observation, summary and grouping. The method of generalization and synthesis has created an opportunity to accumulate the entire spectrum of scientific results obtained in a single concept, reflecting the importance of building an up-to-date and comprehensive mechanism of corporate environmental responsibility. The use of the comparison method facilitated a comparative assessment of the current and expected priorities of corporate environmental responsibility, the adaptation of which should expand the potential of environmental management. The application of summary and grouped methods has created an information base for highlighting motivational criteria and principles of responsible behavior of business structures in the field of environmental development.

\section{Findings}

Achieving sustainable development goals is a strategic priority for the functioning of socioeconomic systems on a global scale. The relevance of sustainable development is declared in the UN convention and promoted by the entire progressive world community. Thus, at this stage of the functioning of the world community, the key paradigm is the achievement of sustainable development goals. The accepted paradigm of sustainable development includes seventeen goals, which are grouped into four main categories:

-economic goals that are associated with the elimination of poverty, reduction of economic inequality, provision of progressive economic growth, responsible consumption;

-environmental goals, which include the use of "green" technologies, climate protection from anthropogenic impact, preservation of territorial ecosystems, the use of alternative energy sources;

-social goals, including the reduction of social inequality, the elimination of hunger, the formation of a healthy generation, the provision of gender equality, the creation of conditions for quality education and decent work, social protection;

-institutional goals that determine the formation of world justice and partnerships between socioeconomic systems, the promotion of common interests of stable existence (Rasteryaev, 2018).

Exploring the role of business structures in shaping the trajectory of sustainable development, Alexandrova (2019) notes the relevance of the environmental responsibility of business entities to ensure the required level of sustainable development. The environmental responsibility of corporations is highly correlated with the achievement of the goals of the ecological block of sustainable development. In this regard, Kostin (2021) and Smirnov (2019) consider it necessary to outline the most urgent priorities of environmental corporate responsibility, the content of which is as follows:

-maximum attention to anthropogenic impacts on the environment during production and economic activities. Thorough study of both current and long-term environmental effects and minimization of negative consequences for ecosystems based on the results of the functioning of the economic and economic complex; 
-diagnostics of all ranges of environmental risks, as well as activation of environmental risk management mechanisms to minimize or completely prevent the occurrence of adverse environmental events;

- adaptation of innovative mechanisms that help reduce the negative impact of the production and economic system on the external environmental environment and lead to minimization of potential environmental risks;

- reorientation of technologies and the general vector of functioning of the production and economic system for the production of the maximum amount of environmentally friendly products, relevant both for maintaining human health and for stabilizing the ecological background of the ecosystem;

- the formation of a "green" trajectory for the use of predominantly alternative energy sources in the economic and economic activities of corporations, which significantly reduce negative emissions into the ecosystem and lead to minimization of potential environmental risks.

The relevance of the implementation of the mechanism of corporate environmental responsibility in the context of achieving sustainable development goals is confirmed in the materials of scientific publications (Eskiev, 2020; Kostin, 2021; Matova, 2020). The analysis of the selected spectrum of scientific material made it possible to group the basic principles of environmentally responsible behaviour of business structures in modern society in Figure 1.

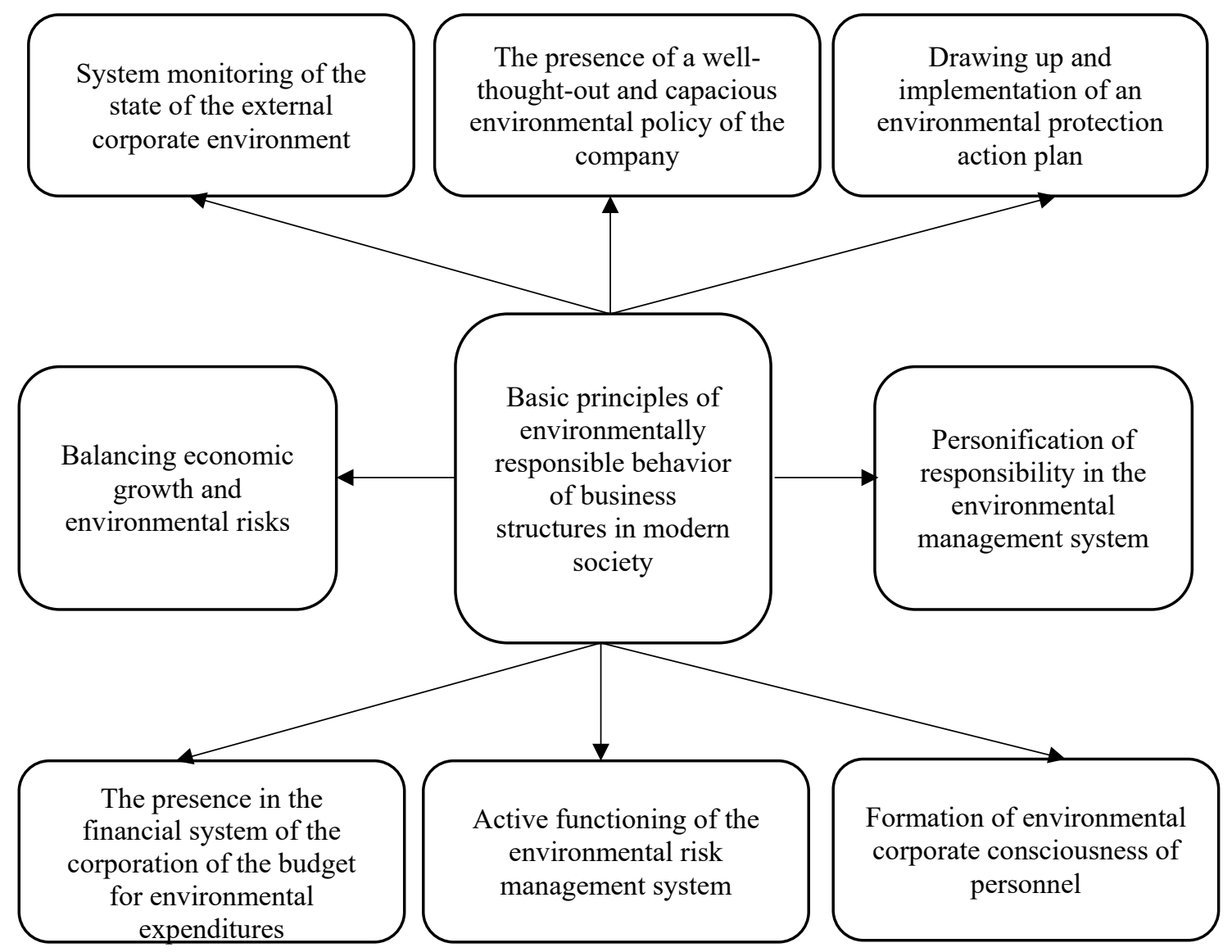

Figure 1. Basic principles of environmentally responsible behavior of business structures in modern society 
In general, it should be noted that the construction of a mechanism for the environmental responsibility of corporations should be based on the adaptation of the principle of prevention. This principle is the cornerstone of the entire environmental management mechanism, the vector of which is aimed at preventing negative environmental events and minimizing environmental risks. Figure 2 presents the hierarchy of levels of corporate environmental responsibility in the context of strategic development.

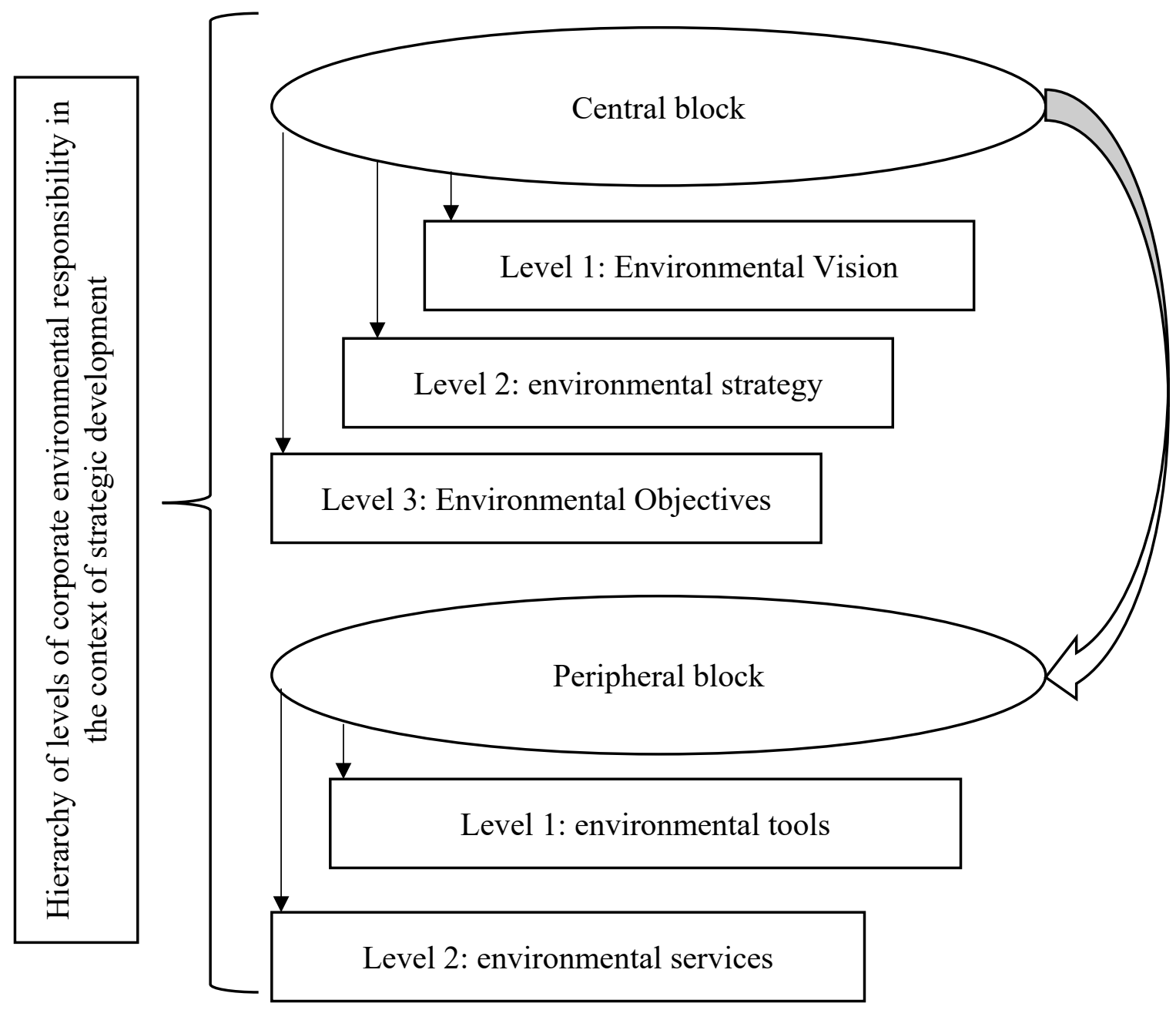

Figure 2. Hierarchy of levels of corporate environmental responsibility in the context of strategic development

Solving problems in the field of corporate environmental responsibility has a rather capacious motivational component. The motivation for responsible behaviour of business structures in the field of environmental development is determined by the following set of reasons:

-the presence of a rather tough imperative legal field with regard to ensuring the ecological safety of ecosystems. The domestic legal field in this area contains rather stringent mechanisms of legal regulation of the environmental responsibility of corporations, which are relevant in nature and are clothed with a wide range of sanctions and administrative measures;

-the need to form a general external background of an environmentally responsible organization in order to create a positive corporate image, which, in turn, is quite closely correlated with the financial results of commercial activities; 
-declaration of long-term ideas and principles of sustainable development, which require compliance with specific measures, including in the implementation of environmental protection (Melnik, 2020).

The development of directions for expanding the potential for environmental responsibility of corporations should be based on diagnostics of the current state of functioning of the environmental management system. As part of the work, the author presents a methodology for calculating several fundamental indicators that allow one to assess the current level of development of corporate environmental responsibility. These indicators include the overall coefficient of environmental activity:

$$
\mathrm{C}_{\mathrm{eaf}}=\frac{\mathrm{Cec}}{T c s}
$$

$\mathrm{C}_{\text {eaf }}$ - corporation environmental activity factor;

$\mathrm{Cec}$ - corporate environmental costs;

Tcs - total corporate spending.

The coefficient of the ecological capacity of equipment, to determine which the following formula is used:

$$
\mathrm{C}_{\text {ecf }}=\frac{\text { Crseu }}{\text { Tceu }}
$$

$\mathrm{C}_{\text {ecf }}$ - equipment environmental capacity factor;

Crseu - the cost of resource-saving equipment used in the framework of economic and economic activities;

Tceu - total cost of equipment used.

The degree of intensity of the use of "green" technologies in the activities of the corporation can be estimated based on the coefficient of environmental manufacturability, which is determined by the following formula:

$$
\mathrm{C}_{\mathrm{emf}}=\frac{\text { Cgtu }}{\text { Tctp }}
$$

где $\mathrm{C}_{\mathrm{emf}}$ - ecological manufacturability factor;

Cgtu - the cost of green technologies used in the framework of economic and economic activities;

Tctp - the total cost of the technological potential of the corporation.

The environmental responsibility of a corporation serves as a basic element of general corporate sustainability, the expression of which is the conduct of such economic and economic activities, which in turn leads to minimization of environmental risks and a decrease in anthropogenic impact on ecosystems of different levels. A manifestation of the corporation's environmental responsibility is the drafting and implementation of an environmental protection action plan, the balance of economic growth and environmental risks, systemic monitoring of the state of the external corporate environment, and the active functioning of the environmental risk management system. 


\section{Conclusion}

Thus, we can conclude about the indisputable role of business structures in achieving sustainable development goals at the present stage of the functioning of world economic relations and existing social and social values. The solution to this problem is based on building a system of balanced mutual interests. The main criteria for building a balance of sustainable development is the correlation of the company's current interests, the vector of which is primarily aimed at maximizing profits, and the interests of preserving the resource potential of socio-economic systems for future generations. At the same time, the environmental responsibility of the corporation must meet the requirement of balance. The presence of a balance of current needs and protection of future interests is the basis for rational economic and economic activity within the framework of the ecological development trajectory. The main instruments for achieving sustainable corporate environmental responsibility status are:

-active functioning of the environmental risk management system;

-the presence in the financial system of the corporation of the budget for environmental expenditures;

-formation of environmental corporate consciousness of personnel;

-system monitoring of the state of the external corporate environment;

-the presence of a well-thought-out and comprehensive environmental policy of the company;

-drawing up and implementation of a plan of measures for environmental protection;

-personification of responsibility in the environmental management system;

-balancing economic growth and environmental risks.

Expanding the potential of these tools is an urgent direction for strategic changes in the corporation's management system. In the context of the above, it should be noted that corporate environmental responsibility characterizes the balanced development of an enterprise, which combines the interests of earning income in the current time and minimizing damage to future generations.

\section{References}

Alexandrova, T. V. (2019). Development of corporate environmental responsibility of oil and gas business in the transition to a "green" economy. Management consulting, 9(129), 55-70. https://doi.org/10.22394/1726-1139-2019-9-55-70

Eskiev, M. A. (2020). Conceptual model of sustainability of the strategic development of industrial companies on the basis of ensuring proper corporate governance. Bulletin of the Academy of Knowledge, 2(37), 403-407.

Kostin, P. A. (2021). On the study of the modern paradigm of environmental responsibility of business. Law and Practice, 2, 245-249.

Matova, N. I., \& Mishulina, S. I . (2020). Socio-ecological responsibility of business: essence, factors of formation, features of manifestation. Bulletin of the Volgograd State University. Economy, 22(3), 123-137. https://doi.org/10.15688/ek.jvolsu.2020.3.11

Melnik, M. V. (2020). Ensuring the economic security of corporate structures. Innovative development of the economy, 6(60), 310-318.

Rasteryaev, K. O. (2018). The concept of management of sustainable development of the company in modern conditions. Management of economic systems: electronic scientific journal, 5(111), 13-17.

Smirnova, O. A. (2019). Environmental responsibility of business. Materials of the All-Russian Scientific and Practical Conference. Saint Petersburg State University of Industrial Technologies and Design. 